\title{
灵国pubvet
}

https://doi.org/10.31533/pubvet.v15n11a956.1-13

\section{Peste suína Africana: Revisão}

\section{Leonardo Martins Nogueira ${ }^{1 *} \bullet$, Maria Eduarda Mirabelo Oliveira ${ }^{1} \bullet$, Giulia Marcondes de Miranda Dariani $^{1}{ }^{\ominus}$, Ana Victória Santana Carvalho ${ }^{1}$, Daniel Francisco Pita Pedro ${ }^{1}$, Lya Von Sudovec Somogyi $^{10}$, Márcia Nishizawa ${ }^{2}{ }^{\circ}$}

${ }^{1}$ Discente do curso de Medicina Veterinária na Universidade Anhembi Morumbi, São Paulo, SP - Brasil.

${ }^{2}$ Docente do curso de Medicina Veterinária na Universidade Anhembi Morumbi.

*Autor para correspondência, E-mail: leomnog@outlook.com

Resumo. A Peste Suína Africana é uma doença infecciosa viral que acomete porcos domésticos e javalis selvagens. É mundialmente considerada como uma das doenças mais importantes na suinocultura, em virtude do grande impacto econômico que é capaz de provocar nos plantéis. Pode ser transmitida diretamente entre os animais, ou através do carrapato vetor, e os indivíduos acometidos podem apresentar a doença de diversas formas: desde formas assintomáticas até formas graves, compreendendo um complexo mecanismo de patogenia, o que pode dificultar a detecção da doença, mesmo havendo métodos e protocolos diagnósticos. Não há tratamento ou vacina disponível, e a prevenção é a melhor forma de controlar a expansão do vírus e evitar novos casos.

Palavras-chave: Infecção, suíno, suinocultura

\section{African swine Fever: Review}

\begin{abstract}
African Swine Fever is an infectious viral disease that affects domestic pigs and wild boars. It's worldwide considered as one of the most important diseases in pig farming, due to the great economic impact it's capable of causing in farms. It can be transmitted directly between the animals, or through the vector tick, and the infected individuals may present the disease in different forms: from asymptomatic forms, to severe ones, with a complex pathogeny mechanism, which may difficult the disease's detection, even having diagnostic methods and protocols. There's no treatment or vaccine available, and prevention is the best way of controlling the virus' expansion and avoiding new cases.
\end{abstract}

Keywords: Infection, swine, pig farm

\section{Introdução}

A Peste Suína Africana (PSA) é uma doença infectocontagiosa provocada pelo Vírus da Peste Suína Africana (VPSA), um arbovírus, que acomete os suínos domésticos e selvagens. O vírus não é capaz de infectar humanos, portanto, não é uma zoonose. É uma das afecções mais relevantes na suinocultura, em decorrência do grande impacto produtivo e econômico que pode provocar sobre os plantéis (Caron, 2019; Soto, 2019). Foi detectada pela primeira vez em meados de 1920 e, desde então, foi capaz de se disseminar em diversos países em todos os continentes, com destaque aos países europeus, que sofreram intensas perdas produtivas em decorrência de surtos e, no cenário atual, países da Eurásia que ainda enfrentam a PSA (Gaundreault et al., 2020; Penrith, 2009). Muitos países, como o Brasil, foram capazes de promover sua erradicação pela implementação de programas sanitários bem estruturados que fornecem diretrizes e buscam padronizar a suinocultura a nível nacional (MAPA, 2019)

A transmissão do VPSA se dá de diversas formas, podendo ser por via direta, pelo contato entre animais sadios e doentes, ou indireta, pelo ambiente contaminado, como fômites, uniformes de 
funcionários, carcaças de animais mortos ou do carrapato vetor do gênero Ornithodoros sp. (Gava et al., 2019; Soto, 2019). No animal, o vírus é capaz de infectar diversas células e compreende um complexo mecanismo de replicação viral. A disseminação do agente no organismo é rápida, e provoca uma série de alterações morfofuncionais importantes, como necrose de tecidos em decorrência de extensa lise celular (Andrés, 2017; Salguero, 2020). Clinicamente, a PSA pode se apresentar de diversas formas de acordo com as manifestações dos animais acometidos. Podem não apresentar sintoma algum, caracterizando quadros assintomáticos, como podem manifestar sinais leves, moderados e graves. Isso é determinado pela virulência da cepa do vírus presente no plantel (Blome et al., 2020; $\underline{\text { Salguero, 2020; }}$ Sánchez-Vizcaíno et al., 2019).

O diagnóstico da PSA envolve diversos fatores e aspectos passíveis de avaliação. Leva-se em conta os achados clínicos nos pacientes, e também é possível a realização de provas laboratoriais para detecção de anticorpos, do agente, entre outros (Gava et al., 2019; OIE, 2019). Há manuais disponíveis que foram elaborados por agências internacionais, como a Organização das Nações Unidas para Alimentação e Agricultura (FAO) e a Organização Mundial da Saúde Animal (OIE), que fornecem diretrizes e protocolos que podem ser adotados para detecção da doença. Ademais, o diagnóstico da PSA auxilia diretamente no controle epidemiológico como um instrumento de vigilância (MAPA, 2020; FAO, 2017; OIE, 2019).

No que diz respeito ao tratamento, por ser provocada por um vírus, não há medidas que podem ser adotadas no combate ao agente, uma vez que este infecta o animal. Com isso, procura-se ressaltar a importância da adoção de medidas profiláticas que sejam eficazes no controle da doença (FAO, 2017; Gava et al., 2019; MAPA, 2020).

Neste trabalho, procurou-se realizar uma revisão de informações disponíveis referentes aos tópicos aqui apresentados, que serão profundamente abordados a seguir. Assim, Para a elaboração deste trabalho, realizou-se um levantamento de informações, em sua maioria recentes, a partir de artigos científicos, revistas, fichas técnicas, manuais, e-books, atlas e livros

\section{Etiologia}

De acordo com Gava et al. (2019), "a peste suína africana é uma doença altamente contagiosa, causada por um vírus composto por DNA fita dupla (Figura 1), pertencente à família Asfaviridae." O vírus, denominado Vírus da Peste Suína Africana (VPSA) possui conformação icosaédrica sendo altamente resistente no ambiente (Liu et al., 2019; Sánchez-Cordón et al., 2019), podendo se apresentar por longos períodos em carcaças de animais acometidos que foram a óbito (Caron, 2019).

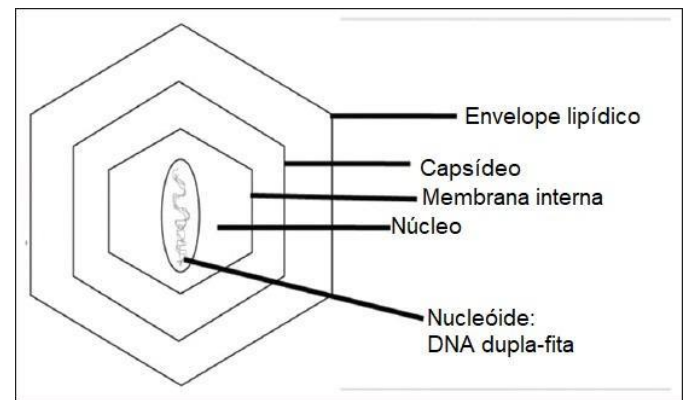

Figura 1. Representação esquemática da estrutura do VPSA. Fonte: Adaptado de Patil et al. (2020).

De acordo com Soto (2019), "o vírus pode permanecer totalmente viável por até uma semana nos dejetos dos suínos e em alimentos crus e cozidos". A resistência do vírus garante alta viabilidade do mesmo por longos períodos na pele de animais ou seres humanos, o que favorece a disseminação da doença nos plantéis (Soto, 2019).

O VPSA pode se apresentar de diferentes formas em relação à patogenicidade, uma vez que, desde a primeira detecção no Quênia, foram identificadas diversas cepas com variações na virulência, de extremamente patogênicas que podem provocar morte súbita, diversas alterações sistêmicas e lesões em 
órgãos internos, à cepas que apenas resultam em soroconversão (Portugal et al., 2015; Soto, 2019). A patogenicidade é um dado obtido a partir da relação entre o número de animais doentes e o número de animais infectados. Essencialmente, para a PSA, há dois tipos de genótipos de relevância, sendo o primeiro (genótipo I) responsável pelo acometimento assintomático dos animais, dificultando a detecção e o combate e favorecendo a manutenção do ciclo do agente, e o segundo (genótipo II), que apresenta alta patogenicidade, provocando adoecimento de vários animais infectados (Zanella et al., 2016).

O ciclo de transmissão do VPSA envolve uma série de fatores e hospedeiros, como javalis, carrapatos vetores (Ornithodoros sp.) e porcos domésticos (Gava et al., 2019). A transmissão sem intermediação do carrapato pode ser direta ou indireta. A forma direta se dá a partir do contato entre animais sadios e infectados, pois os suínos podem transmitir o vírus por todas as secreções e excreções, incluindo secreções oro nasais, urina e fezes (Soto, 2019). A partir do ambiente contaminado, ocorre a infecção de forma indireta, principalmente por carcaças de javalis infectados anteriormente pelo vírus. A infecção indireta também compreende a contaminação dos animais a partir de fômites, camas, roupas e outros objetos que possam conter material biológico de animais previamente infectados pelo vírus (Caron, 2019; Chenais et al., 2019). A transmissão por vetores, como mencionado, é realizada por carrapatos do gênero Ornithodoros sp. (Figura 2). O vetor se infecta ao morder suínos portadores do vírus ou através do próprio ambiente contaminado, e posteriormente transmite aos animais sadios através de nova mordedura (Gava et al., 2019).
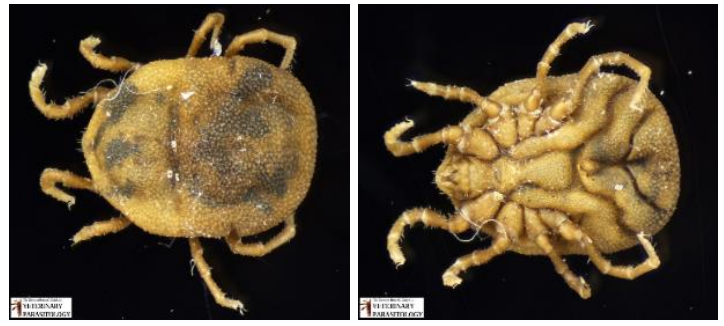

Figura 2. Vista dorsal e ventral, respectivamente, de carrapato do gênero Ornithodoros sp., vetor da PSA. Fonte: Kohls \& Clifford (1963).

O ciclo de transmissão do VPSA, compreendendo os animais acometidos, bem como o vetor, pode ser conferido na Figura 3.

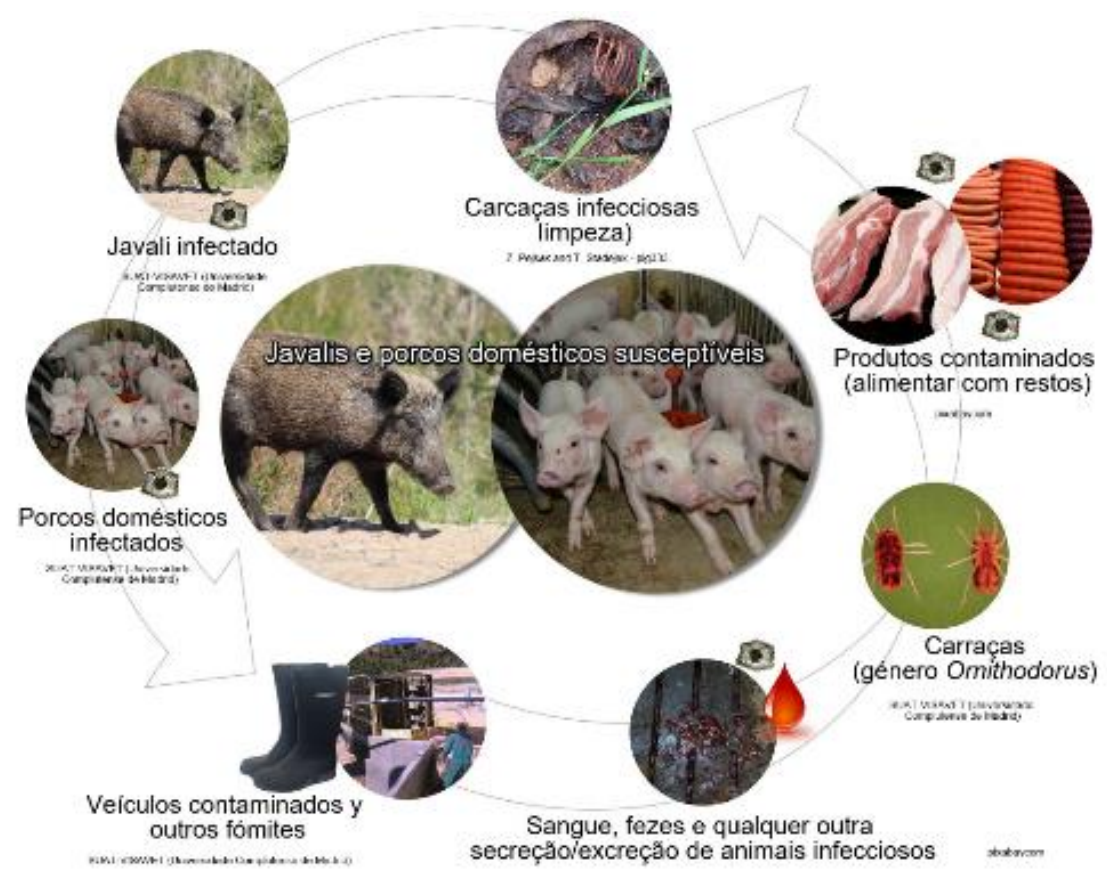

Figura 3. Ciclos de transmissão da Peste Suína Africana. Fonte: Sánchez-Vizcaíno et al. (2019). 
Uma vez dentro do organismo do animal, o VPSA infecta principalmente monócitos e macrófagos, células pelas quais possui predileção, através de endocitose ou macro pinocitose realizada pela célula hospedeira (Andrés, 2017). No total, um ciclo infeccioso completo do VPSA, de adesão e entrada à formação das partículas virais maduras, é completado dentro de 24 hpi ("hours post-infection", ou "horas pós-infecção) (Gaudreault et al., 2020), sendo que este depende de determinadas condições de $\mathrm{pH}$ e temperatura para ocorrer corretamente ( $\underline{\mathrm{OIE}, 2021})$.

\section{Epidemiologia}

A PSA foi identificada pela primeira vez no Quênia, país da região leste do continente africano, em meados da década de 1920. Rapidamente tornou-se endêmica na África, principalmente em países subsaarianos; porém, só despertou interesse da comunidade científica internacional quando passou a causar sérios problemas na Europa em 1957 (Penrith, 2009; Yoo et al., 2020). O primeiro surto de PSA fora do continente africano ocorreu em Portugal, se disseminando com sucesso e causando epidemias através da Península Ibérica na década de 1960. A doença se espalhou com sucesso para outros países europeus ao longo das décadas subsequentes, como, por exemplo, Itália, França e Holanda, e, na década de 1970, chegou às Américas, se disseminando em países como Cuba, sendo este o primeiro país do continente americano a notificar a doença, República Dominicana, Brasil e Haiti (Cwynar et al., 2019; Freitas et al., 2015; Yoo et al., 2020), mas foi erradicada nesses países ao longo dos anos com sucesso. A PSA, entretanto, persistiu na ilha mediterrânea de Sardinia (Itália), onde sistemas de produção ao ar livre, movimentos não-controlados de suínos e fatores socioeconômicos complicaram os esforços para controle (Cwynar et al., 2019). Dados os diversos aspectos que influenciam a permanência da PSA em território africano, a erradicação da doença na região é difícil (Soto, 2019).

Nos anos recentes, foram documentados diversos períodos de surtos esporádicos em alguns países, principalmente da Eurásia. Desde 2007, surtos de PSA em populações de suínos domésticos europeus e russos e o número de casos de PSA entre javalis aumentou dramaticamente. Logo após, uma segunda onda se alastrou, com o primeiro caso sendo identificado na Geórgia, no ano seguinte, na Rússia, e posteriormente na Ucrânia e Bielorrússia, identificados em ambos javalis e suínos domésticos (Gogin et al., 2013; Sánchez-Vizcaíno et al., 2019). A China também sofre com dificuldades para controle da PSA desde essa época. Desde agosto de 2018, a PSA já dizimou cerca de 35\% do rebanho de suínos. De acordo com estimativa realizada pelo MAPA (Ministério da Agricultura, Pecuária e Abastecimento) em 2019, "até 200 milhões morrerão ou serão sacrificados devido a doença, e especialistas afirmam que serão necessários cinco anos para que o país consiga repor o seu plantel tal como era antes do surto". A China é líder mundial na suinocultura, detendo mais da metade do plantel de suínos a nível global. Entretanto, dada a grande extensão do território chinês, as propriedades produtoras são muito heterogêneas, com pouca padronização, o que dificulta o controle da expansão da doença (Soto, 2019). A distribuição da PSA nos países da Eurásia, desde o início da nova onda em 2007, bem como suas consequências aos respectivos plantéis, pode ser verificada no Tabela 1.

A PSA pode demonstrar padrões regionais diferentes de apresentação, associados com um conjunto único de fatores de risco, que devem ser avaliados para estabelecer vigilância e estratégias de controle adequadas (Alonso \& Revilla, 2018). Isso porque os reservatórios naturais da doença variam entre os países, podendo ser o carrapato vetor, ou os próprios animais. Pode-se tomar como exemplo o cenário que ocorreu na Rússia, onde tanto javalis quanto porcos domésticos estavam envolvidos na transmissão, mas carrapatos não. A maioria dos surtos foi encontrada em porcos domésticos e estava associada a movimentos de animais afetados e seus produtos (Brown \& Bevins, 2018). Em javalis selvagens, a letalidade é alta em sua maioria, ou seja, boa parte dos animais que são infectados vão a óbito. Entretanto, a taxa de mortalidade é baixa a moderada, pois apenas uma parcela restrita da população acaba infectada (Schulz et al., 2019).

Apesar da PSA não acometer a espécie humana, o homem é um importante fator no ciclo epidemiológico da doença ao promover a manutenção do vírus na natureza. De acordo com Caron, (2019), "a prática de caça ao javali facilita a disseminação do vírus no ambiente selvagem e doméstico". Isso se dá pelo fato de o vírus, dada sua resistência, permanecer viável nas carcaças dos animais mortos (Caron, 2019). Para entender a dinâmica da doença em diferentes ciclos de transmissão, conhecimento detalhado sobre os envolvidos é necessário. Pode-se verificar intensas variações na suinocultura e, como 
mencionado, a falta de homogeneidade nos plantéis favorece a manutenção do vírus na população (Blome et al., 2020). Apesar de haver fazendas de criação de porcos domésticos que atendem às boas práticas sanitárias e de manejos, o controle da PSA no ambiente produtivo por si só não é suficiente para erradicar a doença, haja vista que os javalis selvagens se encontram submetidos às mais diversas condições de vida (Gava et al., 2019; Sánchez-Cordón et al., 2019; OIE, 2021).

Tabela 1. Distribuição da PSA na Eurásia, de 2007 a 2020.

\begin{tabular}{|c|c|c|c|c|}
\hline País & Ano ou data reportada & Estado & Perda animal estimada & Espécie \\
\hline Geórgia & $2007-2008$ & Resolvido & 87.412 & Suínos \\
\hline Armênia & 2007-2008; 2010-2011 & Resolvido & 2.483 & Suínos \\
\hline Azerbaijão & 2008 & Resolvido & 4.832 & Suínos \\
\hline Rússia & $2007-2019$ & Ativo & 79.632 & Suínos; Javalis selvagens \\
\hline Ucrânia & 2012; 2014-2019 & Ativo & 20.166 & Suínos; Javalis selvagens \\
\hline Bielorrússia & 2013 & Resolvido & 20.627 & Suínos \\
\hline Lituânia & 2014-2019 & Resolvido & 23.735 & Suínos \\
\hline País & Ano ou data reportada & Estado & Perda animal estimada & Espécie \\
\hline Latívia & 2014-2019 & Ativo & 294 & Suínos; Javalis selvagens \\
\hline Estônia & 2014-2019 & Resolvido & 26 & Javalis selvagens \\
\hline Polônia & 2014-2019 & Ativo & 37.396 & Suínos; Javalis selvagens \\
\hline República Tcheca & 2017,2018 & Resolvido & 202 & Javalis selvagens \\
\hline România & $2017-2019$ & Ativo & 90.698 & Suínos; Javalis selvagens \\
\hline Hungria & $2018-2019$ & Ativo & 1.536 & Javalis selvagens \\
\hline Bulgária & $2018-2019$ & Ativo & 137.973 & Suínos; Javalis selvagens \\
\hline Moldávia & 2016-2019 & Ativo & 348 & Suínos; Javalis selvagens \\
\hline Bélgica & $2018-2019$ & Ativo & 540 & Javalis selvagens \\
\hline Eslováquia & 2019 & Ativo & 70 & Suínos; Javalis selvagens \\
\hline Sérvia & 2019 & Ativo & 290 & Suínos \\
\hline China & 2018 & Ativo & 1.193 .000 & Suínos; Javalis selvagens \\
\hline Mongólia & 2019 & Resolvido & 3.115 & Suínos \\
\hline Vietnã & 2019 & Ativo & 5.960 .000 & Suínos \\
\hline Camboja & 2019 & Resolvido & 3.673 & Suínos \\
\hline Coréia do Norte & 2019 & Ativo & 124 & Suínos; Javalis selvagens \\
\hline Laos & 2019 & Ativo & 40.130 & Suínos \\
\hline Filipinas & 2019 & Ativo & 70.000 & Suínos \\
\hline Mianmar & 2019 & Ativo & 128 & Suínos \\
\hline Coréia do Sul & 2019 & Ativo & 10.000 & Suínos; Javalis selvagens \\
\hline Timor-Leste & 2019 & Ativo & 1.600 & Suínos \\
\hline Indonésia & 2019 & Ativo & 42.000 & Suínos \\
\hline
\end{tabular}

Fonte: Adaptado de Gaudreault et al. (2020)

Assim como em outras doenças infecciosas, a taxa de letalidade depende não apenas das características do agente, mas também das populações afetadas, como faixa etária, condições zootécnicas e outros aspectos (Schulz et al., 2019). Outro aspecto relevante é a densidade populacional, uma vez que quanto maior for o número de indivíduos, maior será a transmissão direta entre estes e, consequentemente, a velocidade de disseminação também (Dixon et al., 2020).

\section{Patogenia}

O ciclo infeccioso do VPSA no organismo do hospedeiro provoca importantes alterações morfofuncionais macro e microscópicas, principalmente no sistema linfóide, pelo qual o vírus possui predileção, infectando num primeiro momento as células do sistema monocítico fagocitário, como mencionado no tópico sobre a etiologia da PSA (Andrés, 2017). A maioria dos vírus em geral infectam células hospedeiras através da exploração de um ou mais dos muitos mecanismos celulares endocíticos, como a endocitose mediada por clatrina (CME - Clathrin-Mediated Endocytosis) (Karger et al., 2019; 
Mercer et al., 2010). Entretanto, um estudo publicado por Sánchez-Cordón et al. (2019) revelou que "o mecanismo primário de entrada do VPSA é um processo como macro pinocitose, que envolve perturbações na membrana celular, polarização de actina, atividade de canais de membrana de $\mathrm{Na}+\mathrm{H}+$, e procedimentos de sinalização típicos do mecanismo por macro pinocitose da endocitose". Uma representação das formas de internalização celular, compreendendo endocitose e macro pinocitose, pode ser verificada na Figura 4.

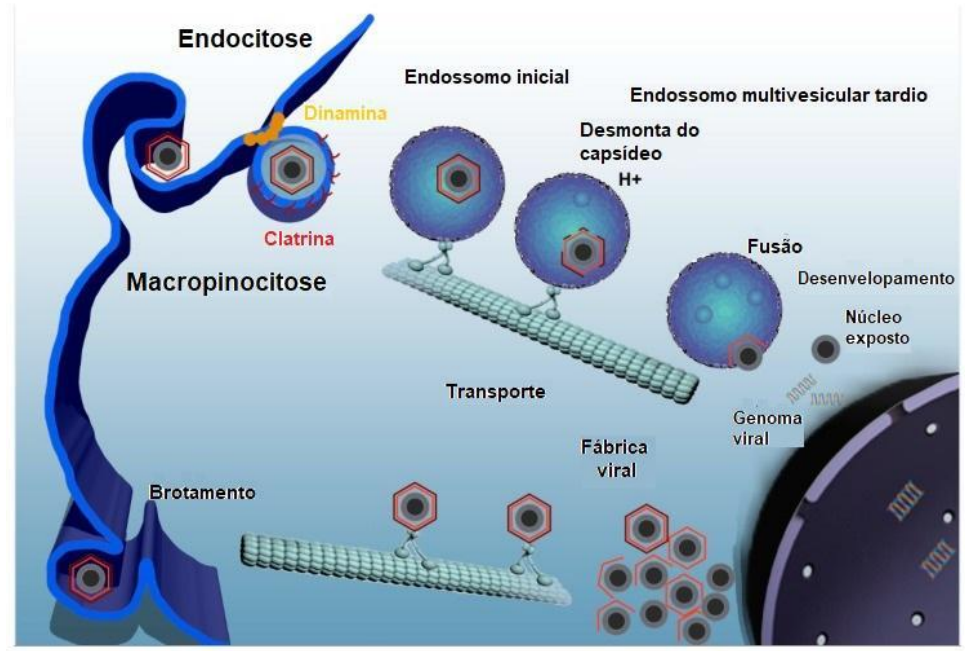

Figura 4. Representação artística das formas de internalização celular compreendidas no ciclo do VPSA. Fonte: Adaptado de Galindo \& Alonso (2017).

Inicialmente, a replicação do vírus se dá em órgãos linfoides próximos à porta de entrada do vírus, geralmente tonsilas ou mucosas faríngeas, dado o tropismo do agente por estes tecidos (Andrés, 2017; Sánchez-Vizcaíno et al., 2019). O vírus segue através da circulação linfática até atingir a via hematógena, provocando viremia. Microscopicamente, os monócitos/macrófagos infectados apresentam-se edemaciados, com marginalização da cromatina nuclear (Salguero, 2020), o que pode ser verificado na Figura 5. Uma característica comum da PSA tanto em javalis selvagens quanto porcos domésticos é a linfoadenomegalia e hemorragia destes órgãos, principalmente em fases tardias da doença (Gomez-Villamandos et al., 2003; Salguero, 2020).

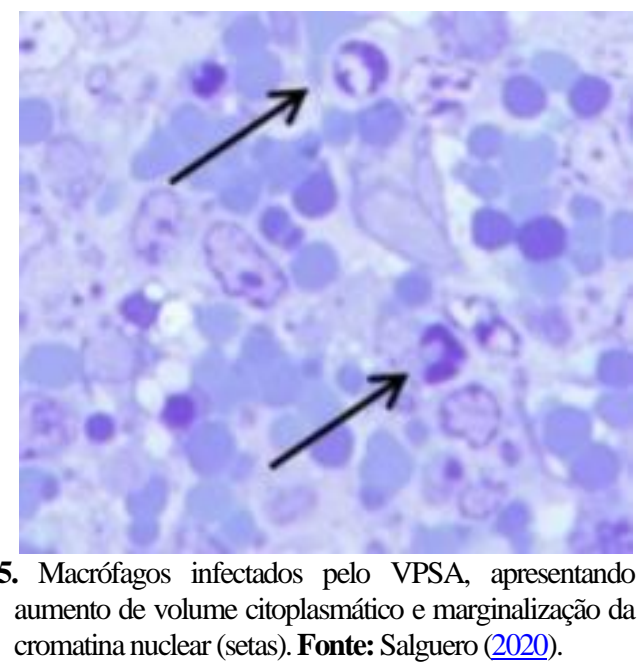

Já na circulação sistêmica, o vírus infecta outras células (como linfócitos, provocando linfopenia) e provocando agressão ao endotélio vascular, até alcançar outros órgãos, como medula óssea, baço, pulmões, fígado e rins. A infecção do VPSA nas células de tais órgãos promove lesão e consequente disfunção dos tecidos, decorrente da replicação viral que, eventualmente, culmina na lise celular por processos tanto necróticos como apoptóticos. No estudo realizado por Rodríguez-Bertos et al. (2020), constatou-se que os mecanismos de replicação do vírus nestes órgãos podem provocar processos 
congestivo, hemorrágico, hiperplásico e inflamatório, além de aumento no volume de órgãos como baço e fígado, e edemaciação de tecidos (Rodríguez-Bertos et al., 2020).

Também são comuns diversas alterações no tecido sanguíneo do hospedeiro, com destaque ao sistema hemostático. Por conta das alterações neste sistema e as lesões endoteliais promovidas pelo vírus, em muitos casos se observa coagulação intravascular disseminada (CID), e o processo está associado com liberação de prostaglandina E2 pelos macrófagos infectados, além de outros mediadores e citocinas, como interleucinas. Em casos avançados e graves, pode-se verificar trombocitopenia em decorrência da destruição de plaquetas, processos imunomediados, ou da infecção da medula óssea, que provoca destruição dos megacariócitos (Gomez-Villamandos et al., 2003; Rodríguez-Bertos et al., 2020).

\section{Manifestações clínicas}

As manifestações clínicas decorrentes da PSA estão intimamente ligadas com os mecanismos de patogenia discutidos. No geral, o período de incubação da doença transita entre 4 e 19 dias, e sinais que os animais podem apresentar são altamente variáveis, dependendo de diversos aspectos, como virulência da cepa, idade dos animais, índices zootécnicos, entre outros (Blome et al., 2020). A PSA pode se apresentar de diversas formas, como hiperaguda, aguda, subaguda, crônica e até assintomática, onde os animais infectados não apresentam sinais de doença, mas ainda sim soroconvertem, variando de quadros onde os animais morrem subitamente com poucos sinais, a casos crônicos associados a uma variedade de sinais inespecíficos, como perda de peso, febre, lesões cutâneas, alterações respiratórias, entre outros (Liu, 2014). A forma hiperaguda geralmente está associada à infecção por cepas de alta virulência, e provoca a morte dos animais acometidos em pouco tempo, com estes apresentando poucos ou nenhum sintoma (Martínez \& Accensi, 2019). Entretanto, nem sempre os casos hiperagudos se apresentam de forma assintomática seguidos de morte súbita, podendo ser caracterizados por um curso clínico muito rápido, com febre alta (até $\left.42^{\circ} \mathrm{C}\right)$, anorexia e letargia ( $\underline{\text { Salguero, 2020)}}$.

A forma aguda se caracteriza por alterações cutâneas, como eritema e hemorragias (igura 6), além de alterações sistêmicas, como anorexia, apatia, cianose, aumento da frequência respiratória, vômito,

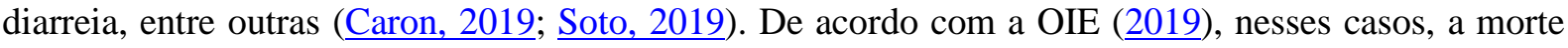
pode ocorrer de 4 a 10 dias. Além disso, as fêmeas prenhes podem abortar. A mortalidade nestes casos é de 30-70\% (Blome et al., 2020).

Os casos subagudos geralmente são caracterizados por febre irregular, que geralmente dura de $30 \mathrm{a}$ 45 dias, seguido de melhora. Podem ser observados piora em índices zootécnicos, como redução da condição corporal, além de manifestações respiratórias, como tosse e dispneia. Quando há morte nesses casos, geralmente ocorre entre 15 e 45 dias (Soto, 2019). Já a forma crônica tem evolução lenta, que varia de 2 a 15 meses e baixa mortalidade. De acordo com Bastos et al. (2014), "A forma crônica da doença geralmente se manifesta em rebanhos previamente expostos e por cepas de baixa a média virulência. Enquanto a mortalidade pode não ocorrer ou, no pior cenário, ser baixa $(\leq 30 \%)$, pode-se encontrar discreta ou severa perda de peso, distúrbios de crescimento e retardação severa de crescimento, perda de pelo, condições febris irregulares, picos respiratórios ondulantes, claudicação associada a artrite, infecções secundárias, e doença de baixo grau perpétua podem ser encontrados em rebanhos de porcos. Porcos cronicamente infectados com PSA não desenvolvem conjuntivite". Além disso, em casos crônicos, os animais podem apresentar sinais dermatológicos importantes como necrose e ulcerações da pele, como pode ser verificado na Figura 7.
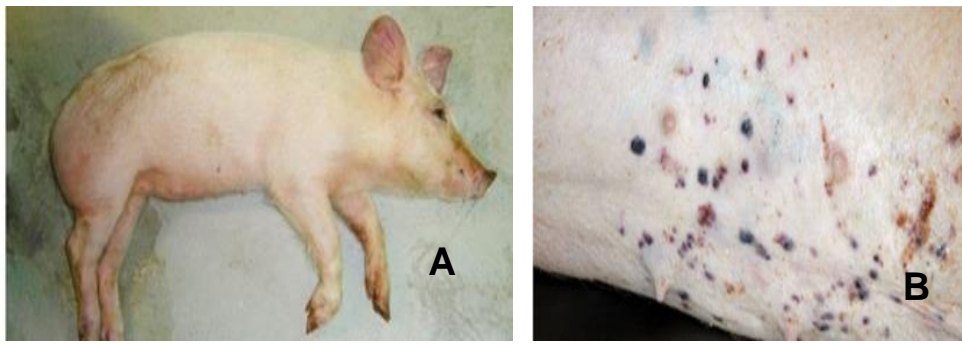

Figura 6. (A) Animal acometido por PSA, apresentando prostração e regiões cianóticas. (B) Na pele, petéquias e equimoses multifocais. Fonte: Salguero $(\underline{2020})$.

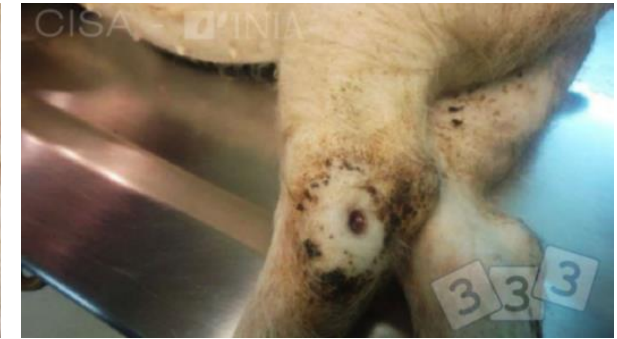

Figura 7. Lesão ulcerativa em pele de suíno acometido por PSA crônica. Fonte: Gallardo (2019). 
Nos casos de PSA subaguda ou crônica, por conta da menor virulência das cepas virais, os animais podem se tornar carreadores do vírus e disseminá-lo por meses, assim como os animais assintomáticos. Neste último caso, apesar da produção de imunoglobulinas, o organismo não é capaz de neutralizar

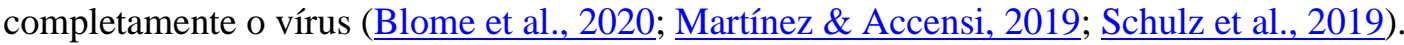

Uma relação de alterações e manifestações passíveis de serem encontradas na PSA de acordo com a gravidade do caso e acometimento dos órgãos pode ser verificada no Tabela 2.

Tabela 2. Distribuição de sintomas da PSA de acordo com a gravidade do caso.

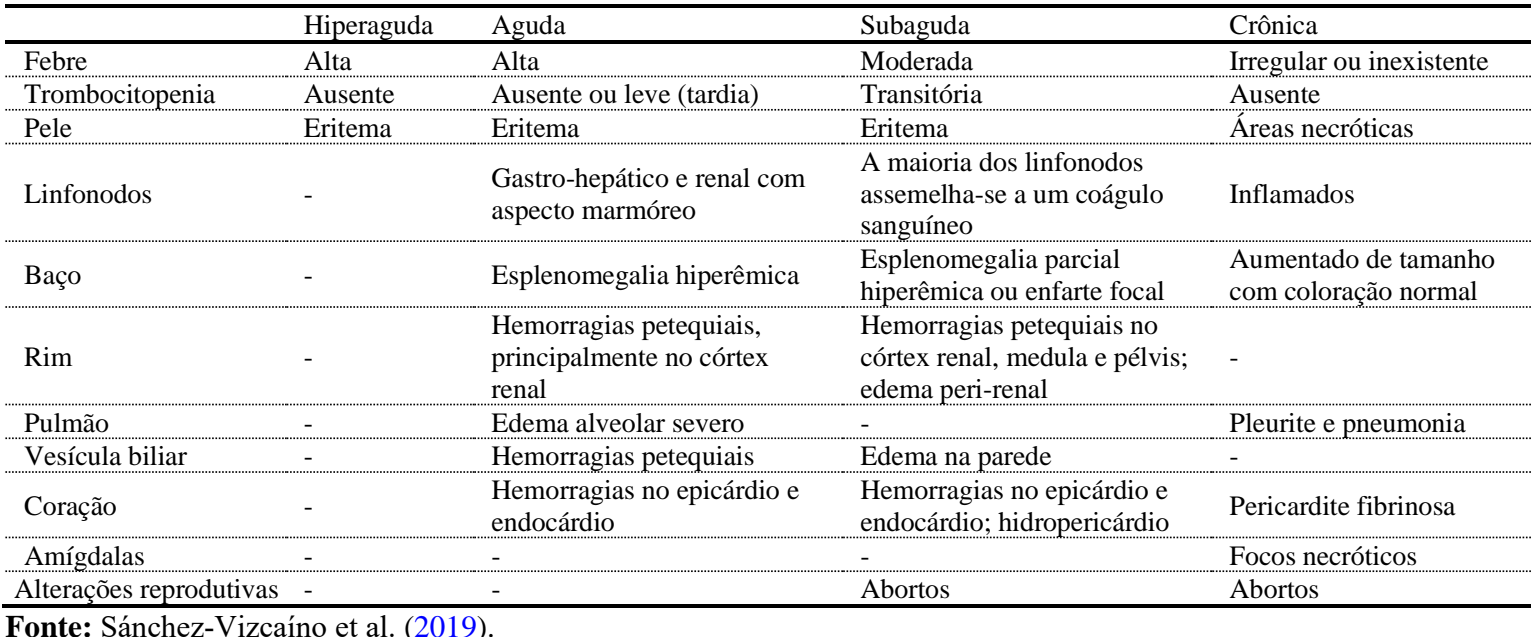

\section{Diagnóstico}

O diagnóstico da PSA, assim como em outras doenças infecciosas, envolve avaliação de diversos fatores. Não apenas aspectos como as manifestações clínicas dos animais acometidos, epidemiologia e distribuição da doença devem ser levados em conta, mas também outras questões como manejo nutricional, instalações da propriedade e outros. Portanto, a avaliação clínica deve ser realizada de forma geral e abrangente, mas ao mesmo tempo minuciosa, além de compreender aspectos laboratoriais e necroscópicos, que são chave no diagnóstico definitivo da PSA. Além disso, o diagnóstico é uma importante medida de controle e vigilância epidemiológica, principalmente na elaboração de medidas de prevenção que sejam eficazes (Gava et al., 2019; OIE, 2019).

A OIE publicou, em 2019, um manual (“OIE Manual of Diagnostic Tests and Vaccines for Terrestrial Animals") com protocolos diagnósticos para diversas doenças, incluindo a PSA. Através de colheita de material biológico dos pacientes, permite a identificação do VPSA direta ou indiretamente, ou seja, detecção do vírus propriamente dito, ou então mensuração dos anticorpos específicos contra o agente. Isso inclui procedimentos como isolamento viral em macrófagos porcinos, Reação em Cadeia da Polimerase em tempo real (RT-PCR), detecção de anticorpos pelas reações enzimáticas (ELISA), "immunoblotting" (técnica que utiliza eletroforese) e técnicas de imunocoloração indireta (OIE, 2019). Dois anos antes da publicação do manual da OIE, em 2017, a Organização das Nações Unidas para Alimentação e Agricultura (FAO) já havia publicado um manual para detecção e diagnóstico da PSA ("African Swine Fever: Detection and Diagnosis"). As informações em ambos manuais vão de encontro, demonstrando que há uma padronização e concordância internacional no que se refere ao diagnóstico laboratorial da PSA (IE, 2019; FAO, 2017).

A avaliação post mortem dos animais através de necrópsia permite a identificação de diversas lesões indicativas de PSA. As lesões mais características encontradas em necropsia se dão na forma aguda da doença, como "eritema cutâneo, esplenomegalia severa, linfoadenopatia hemorrágica; e petéquias nos rins (Figura 8), bexiga urinária e coração" (Figura 8) (Sánchez-Vizcaíno et al., 2019). É comum verificar na avaliação histopatológica destes órgãos processos hemorrágicos e infiltrados inflamatórios intensos, além de alterações na arquitetura tecidual (Figura 9). Como mencionado anteriormente, o diagnóstico definitivo da PSA se dá principalmente pela associação entre achados necroscópicos, colheitas destas 
amostras e envio para análise laboratorial, onde poderão ser verificados ou não a presença do VPSA ou de anticorpos contra este agente (MAPA, 2020; OIE, 2019; Gava, 2019; FAO, 2017).
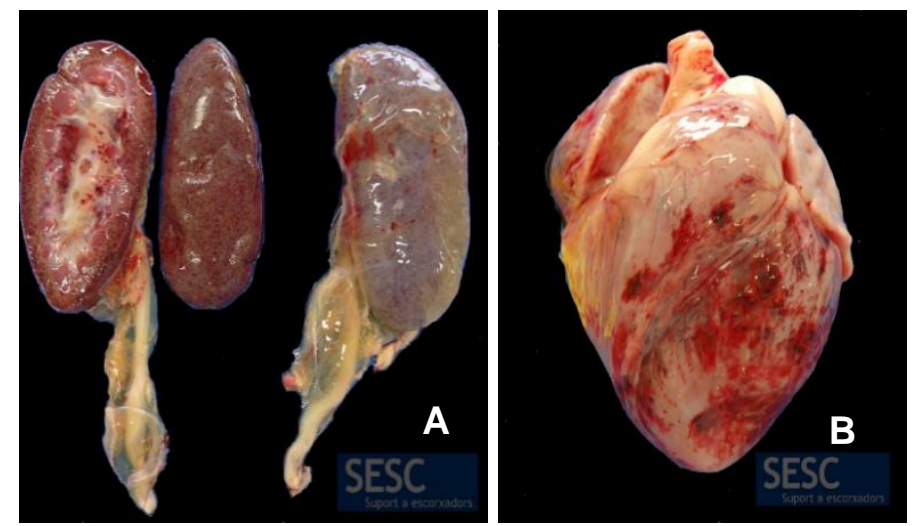

Figura 8. Rins (A) e coração (B) apresentando petéquias distribuídas pelo tecido, lesões comumente encontradas na necrópsia de animais com PSA. Fonte: SESC - Suport a Escorxadors. Disponível em: $\mathrm{http}: / /$ www.cresa.cat/blogs/sesc/lesions-de-pesta-porquinaafricana/?lang=en. Acesso em 21/04/2021.

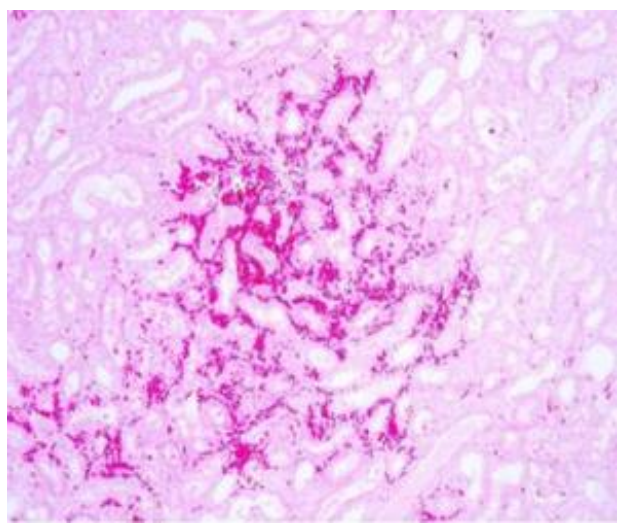

Figura 9. Corte histológico de rim para avaliação histopatológica. $\mathrm{Na}$ imagem, é possível identificar intensa hemorragia intersticial no córtex renal. Fonte: Salguero (2020).

As doenças de diagnóstico diferencial para peste suína africana, de acordo com o MAPA são: "Peste suína clássica (PSC), doença de Aujeszky (DA), PRRS, Circovirose, Salmonelose, Pasterelose, parvovirose, diarreia viral bovina (BVD), leptospirose, erisipela, infecções por Streptococcus sp., Haemophilus parasuis e intoxicação por cumarínicos" (MAPA, 2020).

\section{Tratamento}

Até o momento, não existe tratamento relatado na literatura científica, nem guidelines fornecidas por agências de saúde internacionais. Por se tratar de uma doença provocada por um vírus altamente resistente e que possui diversas cepas, torna-se difícil o combate uma vez que este se instala no organismo do animal. As medidas de controle epidemiológico e prevenção, ainda hoje, são as formas mais eficazes de impedir a disseminação e o surgimento de novos casos nos países onde a PSA ainda não foi erradicada (Gava et al., 2019; OIE, 2019; MAPA, 2020).

\section{Prevenção e controle}

Assim como nas demais doenças infecciosas de etiologia viral, a adoção de métodos de prevenção contra a PSA é a melhor forma de controle, pois evita a proliferação do agente e, se realizados de forma intensa, podem promover a erradicação. Diversos aspectos devem ser levados em conta, como o controle dos animais doentes, manejo ambiental e controle do vetor. No Brasil, de acordo com o MAPA, a presença de um foco de PSA em qualquer porção do território nacional "configura uma situação de EMERGÊNCIA SANITÁRIA", sendo necessária a adoção e implementação de medidas sanitárias visando controlar e evitar a expansão da doença (Alonso \& Revilla, 2018; Gava et al., 2019; MAPA, 2020).

Nos países onde há foco de PSA, é fundamental que seja realizado o sacrifício sanitário de todos os suínos da região, realizando descarte adequado dos cadáveres, e posterior desinfecção completa de todas as instalações (Gava et al., 2019; FAO, 2019). No Brasil, a PSA já foi erradicada, mas o Programa Nacional de Sanidade Suídea (PNSS), elaborado pelo Ministério da Agricultura, Pecuária e Abastecimento (MAPA) e a Empresa Brasileira de Pesquisa Agropecuária (EMBRAPA), realiza constante monitoramento sobre não apenas os plantéis nacionais, mas também os produtos de origem suína que são importados de outros países, na intenção de prevenir aumento do número de casos de doenças já existentes no Brasil, mas também evitar ressurgimento de outras enfermidades, como a PSA (MAPA, 2020). É necessária atuação intensa em fronteiras e alfândegas para que se tenha controle da entrada de produtos de origem suína oriundos de países ou regiões onde há confirmação de PSA, sinalizando as consequências de se entrar no país com estes produtos e indicando locais apropriados para se realizar o descarte (Guberti et al., 2019). De acordo com o MAPA, "um foco de PSA somente 
será encerrado após a eliminação dos animais positivos e comprovação de ausência de circulação viral" (MAPA, 2020).

Em relação à vacinação, até o momento, não há vacina disponível para utilização em protocolos de imunização de suínos. Isso se dá pela alta mutabilidade do agente, o que dificulta o estudo e a produção de um imunizante que seja eficaz e seguro a longo prazo. Ainda assim, há estudos sendo conduzidos com cepas específicas do vírus para desenvolvimento de vacinas, como o de Lopez et al. (2020), que obtiveram resultados interessantes na redução da carga viral e produção de células $T$, mas, como apontado pelos autores, são necessárias futuras pesquisas para avaliar qualitativamente os anticorpos produzidos (Lopez et al., 2020).

$\mathrm{O}$ adequado manejo do ambiente também é um importante fator na promoção do controle da PSA. Isso porque, como comentado, o VPSA é um agente extremamente resistente, capaz de permanecer em superfícies e carcaças de animais mortos infectados por longos períodos, o que favorece a disseminação da doença nos plantéis. Com isso, torna-se necessária a desinfecção adequada das instalações a partir do uso de produtos químicos, ou até por métodos como a vassoura-de-fogo, pois o vírus é destruído quando submetido a altas temperaturas. Em relação às carcaças, a incineração e a graxaria são os métodos mais eficazes e fáceis de realizar o descarte (FAO, 2019; Guberti et al., 2019). Também é possível enterrar as carcaças, sendo necessária a desinfecção da vala caso o cadáver seja removido posteriormente. Esses processos devem ser realizados em locais apropriados e afastados de propriedades de produção suína, pois há risco de contaminação ambiental (FAO, 2019; MAPA, 2020).

Outro aspecto muito importante é a expressão do carrapato vetor nas regiões onde há foco da PSA. É muito importante realizar controle destes parasitas, pois são diretamente responsáveis pela manutenção do VPSA nos ambientes, mesmo que a propriedade produtora atenda todos os requisitos de manejo ambiental adequado. Para países infectados, recomenda-se evitar o contato entre porcos, animais selvagens e vetores de carrapatos moles ou seus habitats (África) e impedir que os animais vagueiem (IE, 2019; FAO, 2019).

\section{Considerações finais}

A Peste Suína Africana é uma afecção de extrema relevância no contexto global da suinocultura, inclusive em países onde já foi erradicada. Apesar de não ter potencial zoonótico e, logo, importância na saúde pública, representa um problema que merece muita atenção, haja vista o grande impacto econômico que a PSA pode acarretar aos produtores. De acordo com estimativa da EMBRAPA, se a PSA fosse reintroduzida no Brasil, a perda econômica provocada pela doença seria de aproximadamente 5,5 bilhões de dólares apenas no primeiro ano, decorrente de diversos aspectos, como morte dos animais, redução de índice zootécnico dos animais doentes, embargos sanitários, impedindo exportações, entre outros.

A transmissão direta entre os animais representa um grande fator de risco por facilitar a rápida disseminação do VPSA, e dificultar o controle da doença uma vez que esta se instala no plantel. Isso é evidenciado pelos surtos documentados em diversos países de 2007 em diante, além do grande número de suínos mortos em decorrência da PSA desde 2018, e as preocupantes projeções realizadas pelo MAPA em 2019, em relação às centenas de milhões de animais que terão de ser sacrificados. Parte da explicação para esse fenômeno se dá à heterogeneidade das propriedades produtoras. A falta de padronização na produção dificulta a implementação de um controle rigoroso e verdadeiramente efetivo, fato que se verifica em diversos países onde ainda são relatados um grande número de casos ativos, como os países da Eurásia. Além disso, outro importante fator que dificulta o controle e favorece a disseminação da doença é a alta resistência do vírus em diversos ambientes, além da existência de cepas com diferentes virulências, capazes de provocar quadros muito variados nos animais, desde doenças brandas a casos extremamente graves. As cepas menos virulentas, que provocam pouca ou nenhuma alteração, muitas vezes passam despercebidas ou são confundidas com outras doenças, e isso acarreta na manutenção destes agentes nas populações. Já as cepas altamente virulentas provocam quadros avançados, intensas manifestações e destruição importante nos tecidos e órgãos. Nestes casos, mesmo a doença sendo extremamente aparente, a evolução é rápida e pouco pode ser feito, havendo morte de muitos animais.

O diagnóstico pode ser um aliado no controle da doença quando realizado de forma adequada. Se a doença é detectada precocemente, é possível adotar uma série de medidas que restrinjam a doença à propriedade, impedindo a disseminação para outros plantéis através de animais selvagens ou vetores. 
Entretanto, isso não se aplica a todos os casos, pois, como mencionado, alguns quadros são brandos e nem sempre há suspeita de PSA, o que favorece a disseminação do vírus. Isso evidencia ainda mais a necessidade de profissionais veterinários qualificados nas propriedades, que sejam capazes de identificar as doenças de acordo com as manifestações e a distribuição regional.

Ainda assim, mesmo havendo a detecção e confirmação da doença, por se tratar de uma infecção viral, não há tratamento específico dos doentes. Com isso, a prevenção torna-se um ponto chave na discussão, uma vez que é a principal maneira de evitar que os animais adoeçam e haja grave impacto econômico. Devem ser adotadas medidas sanitárias adequadas e que atendam aos requisitos básicos estabelecidos pelas agências internacionais, como a OIE, além de órgãos regulamentadores dos respectivos países, como é o caso do MAPA no Brasil, que instituiu o PNSS. Além disso, é necessária a realização de novas pesquisas para que seja possível, eventualmente, desenvolver uma vacina eficaz, segura, e que ofereça proteção contra o maior número de cepas possível.

Levando todos estes aspectos em consideração, é possível concluir que a PSA ainda é uma doença importante no cenário internacional, principalmente por conta de países com medidas de biossegurança ineficientes, que oferecem risco à suinocultura mundial. Um foco de PSA somente será encerrado após a eliminação dos animais positivos e comprovação de ausência de circulação viral. Na conjuntura global, torna-se fundamental a convergência de todos os países para que seja possível alcançar a erradicação.

\section{Referência bibliográficas}

Alcrudo, D. B.; Gallardo, M. A.; Gallardo, C.; Kramer, S. A.; Penrith, M. L. African swine fever: detection and diagnosis. Food and agriculture organization of the United States, [s. 1.], 2017. Disponível em: http://www.fao.org/3/i7228e/i7228e.pdf

Alonso, C., \& Revilla, Y. (2018). African Swine Fever Gap Analysis. GARA, 1, 1-18.

Andrés, G. (2017). African swine fever virus gets undressed: new insights on the entry pathway. Journal of Virology, 91(4), e01906-16.

Bastos, A. D. S., Fasina, F. O \& King, D. P. (2014). African swine fever virus. In: Manual of security sensitive microbes and toxins. $\left[\begin{array}{llllll}S . & l .: & s . & n .\end{array}\right]$ cap. 50. Disponível em: https://www.researchgate.net/publication/261548025_African_swine_fever.

Blome, S., Franzke, K., \& Beer, M. (2020). African swine fever-A review of current knowledge. Virus Research, 287, 1-15.

Brown, V. R., \& Bevins, S. N. (2018). A review of African swine fever and the potential for introduction into the United States and the possibility of subsequent establishment in feral swine and native ticks. Frontiers in Veterinary Science, 5, 1-18. https://doi.org/10.3389/fvets.2018.00011.

Caron, L. (2019). Peste suína africana ou African swine fever. Embrapa Suínos e Aves.

Chenais, E., Depner, K., Guberti, V., Dietze, K., Viltrop, A., \& Ståhl, K. (2019). Epidemiological considerations on African swine fever in Europe 2014-2018. Porcine Health Management, 5(1), 1-10.

Cwynar, P., Stojkov, J., \& Wlazlak, K. (2019). African swine fever status in Europe. Viruses, 11(4), 310.

Dixon, L. K., Stahl, K., Jori, F., Vial, L., \& Pfeiffer, D. U. (2020). African swine fever epidemiology and control. Annual Review of Animal Biosciences, 8, 221-246.

Freitas, T. R. P., Souza, A. C., \& Lyra, T. M. P. (2015). Comparação dos métodos virológicos aplicados no diagnóstico da peste suína africana no Brasil, 1978. Brazilian Journal of Veterinary Medicine, 37(3), 255-263.

Galindo, I., \& Alonso, C. (2017). African swine fever virus: a review. Viruses, 9(5), 103.

Gallardo, C. Úlcera crônica na pata traseira. Disponível em: https://www.3tres3.com.br/atlas/. Acesso em: 14 abr. 2021.

Gaudreault, N. N., Madden, D. W., Wilson, W. C., Trujillo, J. D., \& Richt, J. A. (2020). African swine fever virus: an emerging DNA arbovirus. Frontiers in Veterinary Science, 7, 215.

Gava, D., Zanella, J. R. C., Caron, L., Schaefer, R., \& Silva, V. S. (2019). Peste Suína Clássica e Peste Suína Africana: entendendo as doenças e os riscos para o Brasil. Embrapa Suínos e Aves-, 25(82), 21-26.

Gogin, A., Gerasimov, V., Malogolovkin, A., \& Kolbasov, D. (2013). African swine fever in the North Caucasus region and the Russian Federation in years 2007-2012. Virus Research, 173(1), 198-203. 
Gomez-Villamandos, J. C., Carrasco, L., Bautista, M. J., Sierra, M. A., Quezada, M., Hervas, J., Ruiz-Villamor, E., Salguero, F. J., Sonchez-Cordon, P. J., \& Romanini, S. (2003). African swine fever and classical swine fever: a review of the pathogenesis. DTW. Deutsche Tierarztliche Wochenschrift, 110(4), 165-169.

Guberti, V., Khomenko, S., Masiulis, M., \& Kerba, S. (2019). African swine fever in wild boar ecology and biosecurity. FAO.

Karger, A., Pérez-Núñez, D., Urquiza, J., Hinojar, P., Alonso, C., Freitas, F. B., Revilla, Y., Le Potier, M.-F., \& Montoya, M. (2019). An update on African swine fever virology. Viruses, 11(9), 864.

Kohls, G. M., \& Clifford, C. M. (1963). Omithodoros sparnus sp. n., a Parasite of Wood Rats, Neotoma spp. and Deer Mice, Peromyscus spp. in Utah and Arizona (Acarina: Argasidae). The Journal of Parasitology, 857-861.

Liu, D. (2014). Manual of security sensitive microbes and toxins. CRC Press.

Liu, S., Luo, Y., Wang, Y., Li, S., Zhao, Z., Bi, Y., Sun, J., Peng, R., Song, H., \& Zhu, D. (2019). CryoEM structure of the African swine fever virus. Cell Host \& Microbe, 26(6), 836-843. https://doi.org/10.1016/j.chom.2019.11.004.

Lopez, E., van Heerden, J., Bosch-Camós, L., Accensi, F., Navas, M. J., López-Monteagudo, P., Argilaguet, J., Gallardo, C., Pina-Pedrero, S., \& Salas, M. L. (2020). Live attenuated African swine fever viruses as ideal tools to dissect the mechanisms involved in cross-protection. Viruses, 12(12), 1474.

MAPA. Ministério da Agricultura, Pecuária e Abastecimento (MAPA). Peste Suína Africana (PSA). Governo do Brasil, [s. l.], 27 de maio de 2020. Disponível em: https://www.gov.br/agricultura/pt-br/assuntos/sanidadeanimal-e-vegetal/saude-animal/programas-de-saude-animal/sanidade-suidea/peste-suina-africana-psa

Martínez, J. M., \& Accensi, F. A. (2019). Peste suína africana, uma epidemia que percorre a Europa. Albéitar, 2, 4-7.

Mercer, J., Schelhaas, M., \& Helenius, A. (2010). Virus entry by endocytosis. Annual Review of Biochemistry, 79, 803-833.

Patil, S. S., Suresh, K. P., Vashist, V., Prajapati, A., Pattnaik, B., \& Roy, P. (2020). African swine fever: A permanent threat to Indian pigs. Veterinary World, 13(10), 2275-2285. https://doi.org/10.14202/vetworld.2020.2275-2285.

Penrith, M.-L. (2009). African swine fever. Onderstepoort Journal of Veterinary Research, 76(1), 9195. https://doi.org/10.1016/j.antiviral.2019.02.018.

Portugal, R., Coelho, J., Hoeper, D., Little, N. S., Smithson, C., Upton, C., Martins, C., Leitao, A., \& Keil, G. M. (2015). Related strains of African swine fever virus with different virulence: genome comparison and analysis. Journal of General Virology, 96(2), 408-419. https://doi.org/10.1099/vir.0.070508-0.

Rodríguez-Bertos, A., Cadenas-Fernández, E., Rebollada-Merino, A., Porras-González, N., MayoralAlegre, F. J., Barreno, L., Kosowska, A., Tomé-Sánchez, I., Barasona, J. A., \& Sánchez-Vizcaíno, J. M. (2020). Clinical course and gross pathological findings in wild boar infected with a highly virulent strain of African swine fever virus genotype II. Pathogens, 9(9), 688.

Salguero, F. J. (2020). Comparative pathology and pathogenesis of African swine fever infection in swine. Frontiers in Veterinary Science, 7, 282.

Sánchez-Cordón, P. J., Nunez, A., Neimanis, A., Wikström-Lassa, E., Montoya, M., Crooke, H., \& Gavier-Widén, D. (2019). African swine fever: disease dynamics in wild boar experimentally infected with ASFV isolates belonging to genotype I and II. Viruses, 11(9), 852. https://doi.org/10.3390/v11090852.

Sánchez-Vizcaíno, J. M., Laddomada, A., \& Arias, M. L. (2019). African swine fever virus. Diseases of Swine, 443-452.

Schulz, K., Conraths, F. J., Blome, S., Staubach, C., \& Sauter-Louis, C. (2019). African Swine Fever: Fast and furious or slow and steady? Viruses, 11(9), 866.

Soto, F. R. M. (2019). Peste Suína Africana. Boletim APAMVET, 23-26.

World Organization For Animal Health. African Swine Fever. In: World Organization For Animal Health. African Swine Fever. [S. l.], 2021. Disponível em: https://www.oie.int/en/disease/africanswine-fever/\#searchform-header

World Organization For Animal Health. African Swine Fever. OIE Technical Disease Cards, [s. l.], Junho 2019.2 Disponível em: https://www.oie.int/fileadmin/Home/esp/Our_scientific_expertise/docs/pdf/AFRICAN\%20SWINE $\%$ 20FEVER.pdf 
World Organization For Animal Health. Suidae: African Swine Fever (Infection With African Swine Fever Virus). Separata De: World Organization For Animal Health (org.). OIE Terrestrial Manual. $\left[\begin{array}{llllll}S . & l .: & s . & n .\end{array}, \quad 2019 . \quad\right.$ cap. 3.8.1. Disponível em: https://www.oie.int/fileadmin/Home/eng/Health_standards/tahm/3.08.01_ASF.pdf

Yoo, D., Kim, H., Lee, J. Y., \& Yoo, H. S. (2020). African swine fever: Etiology, epidemiological status in Korea, and perspective on control. Journal of Veterinary Science, 21(2). https://doi.org/10.4142/JVS.2020.21.E38.

Zanella, J. R. C., Morés, N., \& Barcellos, D. E. S. N. (2016). Principais ameaças sanitárias endêmicas da cadeia produtiva de suínos no Brasil. Pesquisa Agropecuária Brasileira, 51(5), 443-453. https://doi.org/10.1590/S0100-204X2016000500004.

Histórico do artigo:

Recebido: 11 de junho de 2021

Aprovado: 25 de julho de 2021
Licenciamento: Este artigo é publicado na modalidade Acesso Aberto sob a licença Creative Commons Atribuição 4.0 (CC-BY 4.0), a qual permite uso irrestrito, distribuição, reprodução em qualquer meio, desde que o autor e a fonte sejam devidamente creditados. 